\title{
A demissão dos religiosos por ausência ilegítima da casa religiosa após o motu proprio Communis Vita (Parte II)
}

The Dismissal of Religious Relatives for the Illegitimate Absence of the Religious House after Motu Proprio Communis Vita (Pars II)

\section{Valdinei de Jesus Ribeiro ${ }^{1}$}

Resumo: Aos 19 de março de 2019, o Papa Francisco publicou o motu proprio Communis Vita (CV), com o qual fez alguns acréscimos ao cân. 694 do CIC atual, determinando que, a partir de sua entrada em vigor, a ausência ilegítima da casa religiosa nos termos fixados pela norma seja causa de demissão ipso facto, simplificando, assim, o procedimento a ser adotado. Após o estudo da normativa acerca da demissão $a b$ homine facultativa, tendo por causa a ausência ilegítima da casa religiosa prolongada por seis meses (primeira parte do artigo), faz-se necessário clarificar a fattispecie prevista pelo motu proprio $\mathrm{CV}$, o procedimento a
Abstract: On March 19, 2019, Pope Francis published the Motu Proprio Communis Vita (CV), with which he made some additions to the can. 694 of the current Code, determining that, as of its effective date, the illegitimate absence of the religious house under the terms established by the rule is the cause of dismissal ipso facto, thus simplifying the procedure to be adopted. After studying the rules on the dismissal $a b$ homine optional due to the illegitimate absence of the religious house extended for six months (first part of the article), it is necessary to clarify the fattispecie provided for by the Motu Proprio CV,

1 Valdinei de Jesus Ribeiro. Doutor e Mestre em Utroque Iure (Direito Canônico e Civil) pela Pontifícia Universidade Lateranense (Cidade do Vaticano) - título convalidado no Brasil pela PUC-RJ. Especialista em Counseling (Aconselhamento) pelas Faculdades Bagozzi de Curitiba-PR. Graduado em Filosofia pelo Centro Universitário Claretiano de Batatais e em Teologia pela Pontifícia Universidade Salesiana de Roma. Atualmente é professor do Instituto Superior de Direito Canônico Santa Catarina em Florianópolis (SC) e colabora com o Pontifício Instituto Superior de Direito Canônico do Rio de Janeiro - extensão Londrina (PR). É professor da Faculdade Claretiana de Teologia (Studium Theologicum) em Curitiba (PR) e Vigário Judicial Adjunto do Tribunal Eclesiástico Interdiocesano e de Apelação de Curitiba (PR). E-mail: <vjribeiro@brturbo.com.br>. 
ser utilizado nesse caso, como, também, os efeitos jurídicos da demissão dos religiosos que se produzem em qualquer uma das formas de demissão previstas pelo ordenamento jurídico da Igreja.

Palavras Chave: Ausência ilegítima. Demissão ipso facto. Procedimento. Efeitos jurídicos. the procedure to be used in this case, as well as the legal effects of the dismissal of religious that occur in any of the forms of dismissal provided for by the legal order of the Church.

Keywords: Illegitimate absence. Dismissal ipso facto. Procedure. Juridical effects.

\section{Introdução}

Na primeira parte do artigo $^{2}$, constatou-se que a legislação que rege a demissão $a b$ homine facultativa (cân. 696, § 1), prevista para algumas situações, dentre as quais, a ausência ilegítima da casa religiosa, permaneceu inalterada. Por conseguinte, foram recordados os principais aspectos da legislação latina que dela se ocupa. Inicialmente, se procurou esclarecer o que se entende por ausência ilegítima da casa religiosa e quais seriam as fontes de tal ilegitimidade. Além disso, como se tratava de demissão $a b$ homine facultativa, foram explicitados os requisitos necessários para a ela se recorrer, destacando-se a exigência da presença cumulativa e simultânea de quatro notas essenciais a serem demonstradas no processo: graves, externae, imputabiles et iuridice comprobatae. Quanto ao procedimento a ser adotado, foi analisado o quanto contido na legislação acerca da atuação do Superior maior (instrução) e do Moderador supremo (decisão) com os respectivos conselhos. Destacou-se, ainda, a importância das admoestações e a necessidade de se demonstrar no processo a incorrigibilidade do religioso, pois somente por isso a demissão se justifica. Nas outras duas formas de demissão (ipso facto e obrigatória) previstas pela legislação, não se exige a demonstração processual de tal incorrigibilidade, uma vez que a lei a presume. Por fim, recordou-se que o decreto de demissão, antes de ser intimado ao religioso, deve passar por um controle prévio da autoridade eclesiástica competente responsável por

2 Cf. RIBEIRO, Valdinei de Jesus. A demissão dos religiosos por ausência ilegítima da casa religiosa após o motu proprio Communis Vita (Parte I). In: Scientia Canonica. Vol. 2, no 3 (2019) pp. 55-82. 
confirmá-lo, havendo sempre a possibilidade de um ulterior recurso, dentro do prazo previsto pela legislação.

Agora, na segunda parte do artigo, as atenções se voltarão para a demissão ipso facto por ausência ilegítima da casa religiosa prolongada por doze meses sem que seja possível localizar o religioso ausente ${ }^{3}$. O Papa Francisco, aos 19 de março de 2019, publicou uma Carta Apostólica na forma de motu proprio, intitulada Communis Vita $(\mathrm{CV})$, com a qual, no que tange aos religiosos, fez dois acréscimos ao cân. 694 do Código latino (CIC). O documento passou a vigorar desde o dia 10 de abril do mesmo ano. Com tais acréscimos, se procurou dar uma resposta adequada e eficaz para o problema da ausência ilegítima da casa religiosa em uma situação muito específica, explicitada pela própria normativa. O Romano Pontífice reconheceu que nem sempre é possível localizar o religioso e dar certeza jurídica à situação de fato. Justamente por isso, optou por considerar a ausência ilegítima da casa religiosa como causa de demissão ipso facto, caso perdure por doze meses contínuos e a localização do religioso seja algo inviável. Quando tal situação se verificar, a demissão se dará em conformidade com o cân. $694, \S 1,3^{\circ}$, seguindo-se o procedimento previsto pelo cân. 694 , $\S \S 2$ e 3 , o que significa que não se recorrerá à demissão $a b$ homine facultativa, mas, sim, à demissão ipso facto.

No desenvolvimento do tema se tratará da demissão ipso facto, destacando-se a noção, os destinatários e as causas previstas para se aplicar esta forma de demissão, sem perder de vista que as atenções se voltarão apenas para uma causa: a ausência ilegítima da casa religiosa nas condições fixadas pelo legislador. Em seguida, se analisará o procedimento a ser adotado (muito mais simples do que o anterior), a fim de que a demissão possa constar juridicamente. Por fim, se abordará a questão dos efeitos jurídicos da demissão e que independem da forma com a qual se deu.

3 Como a normativa não faz distinção de sexo, toda a vez que no texto for utilizada a palavra "religioso" e/ou a palavra "superior", no singular ou no plural, valerá igualmente para os institutos masculinos e femininos, abrangendo "eles" e "elas", sem qualquer distinção, a não ser que pela natureza das coisas se restrinja o significado ao masculino, como, por exemplo, na menção aos institutos clericais. 


\section{A demissão ipso facto e a ausência ilegítima da casa religiosa}

Esta primeira forma de demissão contida no CIC atual só passou a fazer parte da legislação da Igreja a partir do século XX, com o decreto Quum singulae ${ }^{4}$. O código pio-beneditino (cân. 646, § 1), inspirado nesse decreto, previa a demissão ipso facto em três casos: na apostasia pública da fé católica, na fuga com uma pessoa de sexo diverso e no matrimônio atentado ou contraído. A formulação do cânon suscitou na doutrina muitas discussões a respeito do conceito de apostatae e di fugam arripuerit cum muliere ${ }^{5}$. Para evitar as mesmas polêmicas do passado e, sobretudo, para responder de modo mais adequado à nova realidade, o legislador, mesmo mantendo esta primeira forma de demissão, modificou parte do conteúdo do cân. 646, $\S 1$ do código anterior, substituindo a expressão publici apostatae a fide catholica por a fide catholica notorie defecerit e eliminando a fuga com pessoa de sexo diverso como causa de demissão ipso facto.

Com o motu proprio $C V$, a redação do cân. 694 permaneceu inalterada, pois, o parágrafo primeiro ganhou mais um número e foi acrescentado um terceiro parágrafo, razão pela qual se fala de acréscimo e não propriamente de mudança. Houve, também, uma alteração no cân. 729, aplicável aos institutos seculares, mas como este estudo se ocupa dos religiosos, não haverá qualquer abordagem a respeito do cânon citado.

Na sequência, se apresentará a noção e destinatários desta forma de demissão e se mencionará as três fattispecies contempladas no cân. 694, sendo que o foco, como já observado, se voltará exclusivamente para a terceira fattispecie, uma vez que este artigo se ocupa apenas da ausência ilegítima da casa religiosa.

4 Cf. SACRA CONGREGATIO RELIGIOSORUM. Decr. Quum singulae, 16 mai. 1911. In: AAS 3 (1911) n. 18, 237.

5 Acerca dos problemas doutrinais relativos a essa questão, ver: RIBEIRO, Valdinei de Jesus. La dimissione dei religiosi nella legislazione della Chiesa Latina dal Codice del 1917 al Codice del 1983 con speciale riferimento alle legislazioni particolari. Roma: Pontifícia Università Lateranense, 2000, pp. 22-34. 


\subsection{Noção e destinatários da demissão ipso facto}

Não se encontra na legislação anterior e nem na atual qualquer noção a respeito desta forma de demissão, mas é possível afirmar que a demissão ipso facto é uma expulsão que o direito impõe automaticamente ao religioso que comete determinadas ações, sem que o superior e/ou interessado possam a ela se opor.

Como se trata de uma expulsão automática ${ }^{6}$, que não permite oposição, o religioso não pode se valer do direito previsto pelo cân. 698, o qual prevê a possibilidade de comunicação direta com o Moderador supremo, podendo o primeiro apresentar a sua defesa diretamente ao segundo.

Quanto aos destinatários da norma, isto é, aos sujeitos passivos, o cânon não faz qualquer distinção entre professos de votos perpétuos ou temporários, o que significa que esta primeira forma de demissão se aplica a todos os professos incorporados ao instituto, com exceção dos noviços, valendo igualmente para homens e mulheres.

\subsection{Causas previstas para a demissão ipso facto}

Com os acréscimos feitos ao cân. 694 pelo motu proprio $C V$, agora são três as situações que produzem a demissão ipso facto do instituto: abandono notório da fé católica, matrimônio contraído ou tentado e ausência ilegítima da casa religiosa por doze meses ininterruptos, caso o religioso esteja indisponível ${ }^{7}$.

6 Andrés, ao comentar a expressão "ipso facto" a esclarece: "La legge canonica, basata sul puro fatto e sulla presunta incorreggibilità che la commissione dello stesso dimostra, ha fatto le veci dell'autorità competente per ciò che concerne la dimissione. Alla sua attuazione fanno seguito tutti gli effetti propri, dal momento stesso in cui si produce la specie di reato tipificato. Non si eseguono altri requisiti, tranne quello complementare ed ulteriore della dichiarazione legittima del fatto. Questa non intacca la validità né l'efficacia coercitiva dell'espulsione: anche qualora il superiore non raccogliesse le prove, né dichiarasse i fatti, la dimissione continua ad essere valida". ANDRÉS, Domingo. Le forme di vita consacrata. Commentario teologico - giuridico al Codice di Diritto Canonico. Roma: Ediurcla, 2015 ( $7^{\mathrm{a}}$ Ed.), p. 663.

7 Para um estudo detalhado das duas primeiras fattispecies: RIBEIRO, Valdinei de Jesus. La dimissione dei religiosi nella legislazione della Chiesa Latina dal Co- 
A terceira fattispecie contemplada pelo cân. $694, \S 1,3^{\circ}$ é a principal novidade aportada pelo motu proprio $C V$ :

\author{
§1. Ipso facto dimissus ab instituto habendus est sodalis \\ qui: \\ 3) a domo religiosa illegitime absens fuerit, secundum \\ can. $665 \& 2$, duodecim continuos menses, prae oculis ha- \\ bita eiusdem sodalis irreperibilitate.
}

Segundo o texto, deve-se considerar demitido do instituto, pelo próprio fato, o religioso que tiver se ausentado ilegitimamente da casa religiosa, de acordo com a norma do cân. 665 § 2, por doze meses ininterruptos ${ }^{8}$, tendo presente a indisponibilidade do próprio religioso, uma vez que não deixou qualquer rastro que permita ao Superior maior localizá-lo.

Quanto ao cân. 665, § 2, basta se ater ao que foi exposto na abordagem da demissão ab homine facultativa ${ }^{9}$. Como já observado, nessa forma de demissão não basta que se dê a ausência da casa religiosa para que o religioso seja automaticamente demitido, pois a lei exige um processo no qual deve-se provar a ilegitimidade da ausência

dice del 1917 al Codice del 1983 con speciale riferimento alle legislazioni particolari. Roma: Pontificia Università Lateranense, 2000, p. 159-276.

8 Em relação ao cômputo do tempo, é preciso se ater à normativa codicial. $\mathrm{O}$ tempo pode ser visto como contínuo ou útil (cân. 201). O tempo é contínuo quando computado sem interrupção alguma e, portanto, compreende todos os dias, inclusive os festivos e domingos. Assim, trinta dias contínuos são trinta dias tal como está no calendário. Já o tempo útil é aquele que alguém possui, de fato, para poder exercitar o próprio direito. Por isso, este tempo não corre se a pessoa ignora ou não pode efetivamente agir. Assim, o tempo útil não compreende os dias em que alguém ignorava a notícia da vacância do ofício, os dias de festa, os dias em que a pessoa estava impedida ou impossibilitada de agir seja por qual motivo for. O tempo útil começa a contar da meia-noite do dia seguinte e não se contam as horas do dia já começado. Normalmente os prazos fixados se referem ao tempo contínuo, a não ser que a lei estabeleça outra coisa ou se deduza o contrário considerando a natureza das coisas.

9 Cf. RIBEIRO, Valdinei de Jesus. A demissão dos religiosos por ausência ilegítima da casa religiosa após o motu proprio Communis Vita (Parte I). In: Scientia Canonica. Vol. 2, nº 3 (2019) pp. 60-61. 
e a incorrigibilidade do religioso por meio de duas advertências, dando a ele a possibilidade de se defender. Todavia, quando o religioso desaparece por ao menos doze meses ininterruptos, sem deixar rastro algum, a adoção do procedimento previsto por lei (cânn. 697-700) fica praticamente inviável e, justamente por isso, o Papa Francisco entendeu que seria possível encontrar uma solução bem mais simples para o problema: a demissão ipso facto. A questão é que como a lei exige que a ausência se dê por doze meses ininterruptos, isso significa que caso o religioso retorne à vida comunitária antes de sua ausência completar doze meses e posteriormente volte "sumir" outra vez, a contagem do tempo inicia-se do zero, ou seja, a partir da data da nova ausência após o retorno à vida comunitária, seguindo-se as indicações canônicas para o cômputo do tempo. Na prática, tal estratégia poderá ser utilizada por diversas vezes, caso haja má fé do religioso, não sendo possível utilizar a demissão ipso facto enquanto não se verificar a condição fixada pelo legislador. Uma alternativa para enfrentar o problema seria a abertura do processo de demissão $a b$ homine facultativa, cabendo ao Superior maior demonstrar que a volta provisória à casa religiosa por parte do religioso seria apenas uma simples estratégia para burlar a lei e evitar a demissão ipso facto. Não se trataria, porém, de uma alternativa simples, pois na demissão $a b$ homine facultativa só se poderá proceder com a demissão caso as duas advertências exigidas por lei resultem ineficazes e, também aqui, o problema poderia se repetir, uma vez que é preciso demonstrar a incorrigibilidade. Não se trata de um problema insolúvel, mas é preciso tê-lo presente quando se é obrigado a respeitar determinados procedimentos, tendo em vista a legitimidade da decisão a ser tomada.

Prescindindo da hipótese apenas aventada, na demissão ipso facto o religioso é demitido a partir do momento em que se configura a fattispecie indicada pelo legislador (no caso, a do cân. 665, § 2), independentemente da vontade do seu Superior maior. Além disso, a imputabilidade e a incorrigibilidade do religioso são presumidas por lei, diferentemente do que acontece na demissão $a b$ homine facultativa, 
pois nessa última, a lei exige que a culpa e incorrigibilidade do religioso sejam demonstradas no processo mediante provas ${ }^{10}$.

Na sequência, se analisará o procedimento a ser seguido que, no caso, é muito mais simples do quanto visto anteriormente, já que a lei adotará algumas presunções e o religioso será demitido pelo próprio direito, uma vez ocorrido o fato indicado pela norma.

\subsection{Procedimento a ser adotado (cân. 694, $\S \S 2$ e 3)}

Para as três fattispecies contempladas pelo cân. 694 , § 1, o procedimento a ser adotado é o mesmo indicado pelo cân. $694, \S 2$ :

His in casibus Superior maior cum suo consilio, nulla mora interposita, collectis probationibus, declarationem facti emittat, ut iuridice constet de dimissione.

A competência para declarar o fato é do Superior maior. Conforme o cân. 620, Superiores maiores são os que governam todo o instituto, uma sua província, uma parte a ela equiparada ou uma casa autônoma, bem como seus vigários. A esses acrescentam-se o Abade Primaz e o Superior de congregação monástica que, todavia, não têm todo o poder que o direito universal confere aos Superiores maiores. Sendo assim, são Superiores maiores: o Moderador supremo, o Superior provincial e quase-provincial, o preposto ou Abade e todos os respectivos vigários ${ }^{11}$.

A lei estabelece que o Superior maior deve declarar o fato "com seu conselho". Segundo De Paolis, a validade da declaração do fato não depende da consulta ao conselho nos termos fixados pelo cân.

10 A propósito do procedimento a ser utilizado na demissão ab homine facultativa, ver: cf. RIBEIRO, Valdinei de Jesus. A demissão dos religiosos por ausência ilegítima da casa religiosa após o motu proprio Communis Vita (Parte I). In: Scientia Canonica. Vol. 2, no 3 (2019) pp. 62-82.

11 O superior local, a não ser que se trate de uma casa sui iuris, poderá somente verificar a materialidade dos fatos (recolher as provas), mas a declaração da demissão é de competência exclusiva do Superior maior. Cf. ANDRÉS, Domingo. Le forme di vita consacrata. Commentario teologico - giuridico al Codice di Diritto Canonico. Roma: Ediurcla, 2015 ( $7^{\mathrm{a}}$ Ed.), p. 665. 
$127, \S 1$. Trata-se, apenas, de apresentar ao conselho as provas que demonstrem a ausência ilegítima da casa religiosa por doze meses ininterruptos, juntamente com as tentativas inúteis de localizar o religioso ausente, para que, desta forma, se chegue à certeza moral do fato ocorrido. Não se trata, portanto, de tomar uma decisão e nem mesmo de votar. Uma vez que se chegou à certeza moral do ocorrido, o Superior maior simplesmente declara o fato da demissão já imposta pelo próprio direito ${ }^{12}$. Calabrese sustenta que o conselho não se limita a dar o devido consentimento a ação do Superior maior, pois operaria com ele como um colégio. Portanto, a declaração do fato seria o resultado de uma ação conjunta do Superior maior e do seu conselho ${ }^{13}$. Andrés, por sua vez, afirma que compete ao direito próprio do instituto determinar o tipo de Superior maior que deverá agir e a forma de atuação do seu conselho ${ }^{14}$. Essa última posição parece ser a mais justa porque, de fato, o cânon não oferece qualquer indicação que permita sustentar que a intervenção do conselho deva se dar desta ou daquela maneira. Por conseguinte, é uma questão a ser resolvida pelo direito próprio de cada instituto, como já o previa o código pio-beneditino ${ }^{15}$.

A declaração do fato é necessária para permitir a sua constatação jurídica e, portanto, não tem a finalidade de tornar eficaz a demissão, uma vez que historicamente ela ocorreu antes mesmo da sua declaração. Trata-se simplesmente de uma declaração formal, fundada sobre a verdade dos fatos e não de uma sentença condenatória ${ }^{16}$. Por

12 Cf. DE PAOLIS, Velasio. La vita consacrata nella Chiesa.Venezia: Marcianum Press, 2015, p. 578.

13 Cf. CALABRESE, Antonio. Istituti di Vita Consacrata e Società di Vita Apostolica. Città del Vaticano: Libreria Editrice Vaticana, 2011 ( $3^{\mathrm{a}} \mathrm{Ed}$.) p. 304.

14 Cf. ANDRÉS, Domingo. Le forme di vita consacrata. Commentario teologicogiuridico al Codice di Diritto Canonico. Roma: Ediurcla, 2015 ( $7^{\mathrm{a}}$ Ed.), p. 665.

15 O código pio-beneditino, diferentemente do atual, afirmava que o Superior maior deveria declarar o fato com o seu capítulo ou conselho, "ad normam constitutionum"(cf. can. 646, § 2).

16 A declaração exigida pela norma não é um requisito essencial para a validade da demissão, porque essa já ocorreu antes mesmo da declaração do fato, como bem o recorda Andrés: "La sentenza, parlando propriamente, la emette lo stesso diritto nel presente canone. Ha efficacia ipso facto, cioè nello stesso momento in cui incorse nel fatto tipificato dal diritto; perciò, tale sentenza è storicamente anteriore alla dichiarazione del superiore competente, che si limita a verificare i fatti”. 
esse motivo, é fundamental o recolhimento das provas que atestem o quanto ocorrido.

Calabrese recorda que a declaração do fato deve ser firmada pelo Superior maior e pelos membros do conselho e as provas devem ser anexadas a ela ${ }^{17}$. Jean Beyer, por sua vez, destaca a necessidade de o Superior maior informar a demissão ocorrida ao Moderador supremo ou equiparado ${ }^{18}$.

No caso da demissão ipso facto provocada por ausência ilegítima da causa religiosa por doze meses ininterruptos, e apenas nesse caso, o motu proprio $C V$ estabelece que a declaração do fato, para constar juridicamente, necessita da confirmação da S. Sé (institutos de direito pontifício) ou do Bispo da sede principal (institutos de direito diocesano):

$\S$ 3. In casu de quo in $\S 1 \mathrm{n}$. 3, talis declaratio ut iuridice constet, a Sancta Sede confirmari debet; quod ad instituta iuris dioecesani attinet, confirmatio ad principis Sedis Episcopum spectat.

A exigência de uma confirmação é uma garantia a mais no sentido de verificar se, de fato, se está diante da fattispecie indicada pela normativa. É preciso analisar se a ausência do religioso é ilegítima, se foram feitos todos os esforços para localizá-lo, se a busca não logrou êxito e se a situação permaneceu inalterada por doze meses ininterruptos. Feita essa constatação, comprovada pela documentação produzida e observado o procedimento fixado por lei, cumpre-se o quanto exigido para a confirmação.

ANDRÉS, Domingo. Le forme di vita consacrata. Commentario teologico - giuridico al Codice di Diritto Canonico. Roma: Ediurcla, 2015 ( $7^{\mathrm{a}}$ Ed.), p. 665.

17 Cf. CALABRESE, Antonio. Istituti di Vita Consacrata e Società di Vita Apostolica. Città del Vaticano: Libreria Editrice Vaticana, 2011 ( $3^{\mathrm{a}}$ ed.), p. 305.

18 BEYER, Jean. Le Droit de la Vie Consacrée. Paris: Editions Tardy, 1988, p. 195. 


\subsection{Efeitos jurídicos da demissão}

Os efeitos jurídicos da demissão não foram objeto de tratativa na primeira parte do artigo e, portanto, torna-se necessário deles se ocupar aqui.

A demissão legítima de um religioso, independentemente da forma como se dá, produz sempre os mesmos efeitos. Todavia, se o religioso for clérigo, há uma pequena diferença entre os efeitos da demissão ipso facto e os das outras duas formas previstas e se referem ao exercício do ministério ordenado e não ao estado religioso enquanto tal. A diferença é que as duas primeiras causas de demissão ipso facto (cân. 694, § 1, $1^{\circ}$ e $2^{\circ}$ ) são delitos que comportam a aplicação de penas latae sententiae que impedem o exercício do ministério sagrado. Nos outros casos de demissão (com exceção daquela prevista para o delito prescrito pelo cân. 1398, que também comporta uma pena latae sententiae), o religioso clérigo fica impedido de exercitar as ordens sagradas enquanto não encontrar um Bispo que o receba, após conveniente prova na diocese, de acordo com o cân. 693, ou ao menos lhe permita o exercício das ordens sagradas ${ }^{19}$. Trata-se aqui da aplicação do quanto estabelece o cân. 265 que não admite, de forma alguma, clérigos acéfalos ou vagantes.

Com a publicação do motu proprio Vos Estis Lux Mundi, a conduta tipificada pelo Art. $1, \S 1$ a do documento, passou a ser considerada um delito cujo sujeito ativo não é apenas um clérigo, mas, também, qualquer membro de um Instituto de Vida Consagrada ou de uma Sociedade de Vida Apostólica. Por conseguinte, os sujeitos indicados pela norma, além da demissão, poderão sofrer uma pena canônica ferendae sententiae, dentre as quais a da demissão do estado clerical, caso se trate de um clérigo. Nesta última hipótese, não se trata simplesmente de um impedimento provisório para exercer as ordens até encontrar um Bispo benévolo, mas, sim, de uma pena expiatória perpétua $^{20}$.

19 É improvável que isso ocorra se a demissão se der por abandono notório da fé católica ou por matrimônio contraído ou tentado, mesmo só civilmente.

20 Cf. FRANCISCO. Carta apostólica sob forma de motu proprio Vos Estis Lux Mundi. (on -line) <http://www.vatican.va/content/francesco/pt/motu_proprio/ 
Uma vez efetivada a demissão, o religioso clérigo deverá deixar o instituto, independentemente de ter encontrado, ou não, um Bispo benévolo que o acolha e lhe permita o exercício do ministério, se for esse o caso ${ }^{21}$.

A demissão legítima produz efeitos que recaem sobre quem foi demitido e, também, sobre o instituto. Tais efeitos serão detalhados na sequência.

1.4.1 Cessação dos votos, dos direitos e das obrigações

No cân. 701, o legislador estabeleceu que com a demissão legítima se produzem os seguintes efeitos:

Legitima dimissione ipso facto cessant vota necnon iura et obligationes ex professione promanantia. Si tamen sodalis sit clericus, sacros ordines exercere nequit, donec Episcopum inveniat qui eum post congruam probationem in dioecesi, ad normam can. 693, recipiat vel saltem exercitium sacrorum ordinum permittat.

Conforme o texto, os efeitos se produzem se a demissão for legítima, independentemente da forma como se dá (ipso facto, obrigatória ou facultativa). Isso pressupõe a existência dos delitos previstos pelo direito (cân. 694, § 1, $1^{\circ}$ e $2^{\circ}$ e cân. 695), ou a ausência ilegítima por doze meses ininterruptos (cân. 694, $\S 1,3^{\circ}$ ), ou, ainda, as transgressões indicadas pelo cân. 696. Requer, também, um Superior competente para declará-la ou decretá-la e a observância de todas as formalidades fixadas por lei. Caso o religioso tenha apresentado recurso, tais efeitos ficam suspensos até a decisão final, à norma do cân. 700 .

A demissão legítima produz a automática cessação dos votos (ipso facto). Os votos aos quais se refere o cânon são aqueles públicos,

documents/papa-francesco-motu-proprio-20190507_vos-estis-lux-mundi.html>. Acessado aos 27/02/2020.

21 Se ao invés da demissão, o religioso clérigo pedir para deixar o instituto, o indulto de secularização não poderá lhe ser concedido sem antes se cumprirem as condições fixadas pelo cân. 693 . 
perpétuos ou temporários ${ }^{22}$. Na vigência do código pio-beneditino (cân. 672, § 1) não se previa uma cessação automática dos votos caso o religioso fosse demitido do instituto, exceto se a Santa Sé ou as Constituições tivessem estabelecido diversamente. Sendo assim, se o religioso fosse demitido do instituto, permanecia vinculado aos votos que professou, tendo a obrigação de mudar de vida e retornar ao instituto, a não ser que tivesse obtido a dispensa dos votos. Houve, portanto, uma mudança na atual codificação, pois os votos cessam, o demitido perde o estado religioso e a sua incorporação ao instituto ${ }^{23}$.

O cân. 701 afirma, também, que com a demissão cessam as obrigações decorrentes da profissão. A formulação do texto está diretamente vinculada à precedente, pois a profissão religiosa se emite mediante votos e deles decorrem determinadas obrigações e direitos

22 Segundo o cân. 1191, § 1, o voto é a promessa deliberada e livre de um bem possível e melhor, feita a Deus que deve ser cumprido em razão da virtude da religião. $\mathrm{O}$ voto é público quando aceito pelo superior legítimo em nome da Igreja. Do contrário, é privado (cân. 1192). Para um estudo jurídico sobre os votos públicos: ANDRÉS, Domingo. Le forme di vita consacrata. Commentario teologico - giuridico al Codice di Diritto Canonico. Roma: Ediurcla, 2015 (7 $7^{\mathrm{a}} \mathrm{Ed}$.), p. 102-107.

23 Convém observar que em relação à demissão ipso facto existe uma notável diferença entre a legislação latina e a oriental. No Código das Igrejas Orientais $(C C E O)$, o cân. 502 estabelece uma exceção à regra geral sobre os efeitos jurídicos da demissão relativos à cessação dos votos e de todas as obrigações, pois o religioso demitido ipso facto permanece vinculado aos votos. A razão de tal medida seria a de evitar que o demitido possa tirar algum proveito da própria transgressão, o que ocorreria se lhe fosse concedida a liberação de todos os vínculos e de todas as obrigações decorrentes da profissão monástica. A. Jaeger não concorda com essa visão, posicionando-se da seguinte forma: "Questo ragionamento è facilmente comprensibile, ma non si chiarisce così sufficientemente la situazione (giuridica) concreta, nella quale il religioso dimesso si viene a trovare ora, o come le condizioni così create per il religioso dimesso si concilino con le esigenze della giustizia e del buon senso. Inoltre pensare che la cessazione completa di ogni legame alla vita religiosa precedentemente professata sia da considerarsi in qualche modo un "premio" non sembra dimostri un'alta stima per la vita religiosa. Sembra che ci sia qui una "reliquia" di un passato ormai alquanto remoto, e che si tratti di un elemento che opportunamente potrà essere rivisto". JAEGER, David-Maria A. Alcuni appunti sui religiosi nel Codex Canonum Ecclesiarum Orientalium. In: AA.VV. Il Diritto Canonico Orientale nell'ordinamento ecclesiale. Città del Vaticano: Libreria Editrice Vaticana, 1995, p. 188. 
estabelecidos pela legislação universal e própria. Se os votos cessam, tudo aquilo que está conexo com eles e deles decorrem perde o sentido, razão pela qual não há mais direitos e obrigações ligados ao estado religioso.

Particular atenção requer a situação do religioso clérigo demitido, à qual já foi feita uma breve alusão há pouco. Segundo o texto, se o demitido for um clérigo, não poderá exercer as ordens sagradas até encontrar um Bispo que o receba após conveniente prova na diocese, de acordo com o cân. 693, ou ao menos lhe permita o exercício das ordens sagradas. Há, também, a possibilidade de o religioso clérigo sofrer um processo penal e, como pena, perder o estado clerical, com os efeitos indicados pelo cân. 292.

Embora o cân. 701 seja claro em sua formulação, há um problema discutido em doutrina: a incardinação do clérigo demitido. $\mathrm{O}$ texto se limita a aplicar o quanto estabelecido pelo cân. 265. O religioso clérigo possui um duplo vínculo jurídico com o instituto: aquele decorrente da profissão religiosa por meio da qual foi incorporado ao instituto como religioso (cân. 654 - adscrição) e aquele decorrente da ordenação diaconal, por meio da qual foi incorporado ao instituto como clérigo, à norma do cân. $266, \S 2$. Sendo assim, a questão discutida em doutrina é a seguinte: se após a demissão o religioso clérigo não for acolhido em uma diocese, nem mesmo por um período de prova, mas o Bispo diocesano lhe consentir o exercício das ordens, onde ele está incardinado? E se não encontra um Bispo que lhe permita, ao menos, o exercício do ministério sagrado, como fica a sua situação?

Se o religioso clérigo for um professo de votos temporários, que entrou no instituto após a sua ordenação, deve retornar à diocese na qual está incardinado, pois, em conformidade com o cân. 268 , § 2, tal incardinação só cessa (excardinação) com a profissão perpétua por meio da qual seria incardinado ao instituto como clérigo, o que não ocorreu. Todavia, a questão se coloca quando o religioso se tornou clérigo no instituto após ter sido a ele incorporado definitivamente com a profissão religiosa. Nesse caso, a incardinação como clérigo é posterior à sua incorporação definitiva ao instituto, não havendo, portanto, uma incardinação precedente em diocese alguma. O que dizer? 
Calabrese (não categoricamente) e Jean Beyer defendem a ideia de que o religioso clérigo demitido permanece incardinado no instituto de origem enquanto não ocorrer a incardinação em outra diocese ou Igreja particular ou prelazia pessoal ou em outro instituto de vida consagrada ou sociedade de vida apostólica ${ }^{24}$.

Chiappetta, por sua vez, discorda da permanência da incardinação do religioso clérigo demitido do seu instituto:

Il religioso dimesso a termini del can. 699 non è più membro del suo Istituto. Come tale, non è più incorporato né incardinato ad esso. Un Vescovo lo riceve in prova senza concedergli l'incardinazione. Finché dura questa prova, egli non è incardinato in nessuna diocesi e in nessuno Istituto. È un caso anomalo di chierico "acefalo", in contrasto con la norma generale del can. $265^{25}$.

Egaña procura aprofundar a questão, esclarecendo o sentido da incardinação e assumindo uma posição diferente dos autores há pouco citados. Segundo ele, o conceito de incardinação inclui o serviço a uma Igreja particular, a obediência a um ordinário e a abertura à Igreja universal. Tendo por base o cân. 701, o autor afirma que com a demissão cessam ipso facto os votos e, por conseguinte, os direitos e as obrigações decorrentes da profissão. Sendo assim, o religioso demitido legitimamente do instituto não possui qualquer obrigação em relação ao instituto e aos superiores. Faltam, portanto, os elementos essenciais da incardinação e, justamente por isso, não se poderia afirmar que o demitido continua incardinado no instituto, pois se assim o fosse, tal vínculo não teria consequência jurídica alguma, uma vez que o religioso não está mais obrigado a obedecer os superiores do instituto

24 Cf. BEYER, Jean. La dimissione nella vita consacrata. In: Vita Consacrata 28 (1992) nota 29, p.169; CALABRESE, Antonio. Istituti di Vita Consacrata e Società di Vita Apostolica. Città del Vaticano: Libreria Editrice Vaticana, 2011 (3 ed.), p. 326.

25 CHIAPPETTA, Luigi. Il Codice di Diritto Canonico. Commento giuridicopastoral. Vol. 1, Roma: Edizione Dehoniane, 1996, p. 849. 
e esses, por sua vez, não teriam qualquer meio para urgir a obediência canônica no exercício do ministério ordenado ${ }^{26}$.

Egaña diverge também da posição de Chiapetta o qual, mesmo reconhecendo a falta de incardinação durante o período de prova, sustenta que o clérigo se tornaria "acéfalo", identificando não incardinação com acefalia. Segundo Egaña, a falta de incardinação não faz com que o clérigo se torne automaticamente "acéfalo" ou "vagante". O conceito de clérigo "acéfalo" ou "vagante" não se identifica com o conceito de clérigo não incardinado. $\mathrm{O}$ primeiro, indica o clérigo não submetido à jurisdição de um Bispo. Para o autor, o direito aceita a existência de clérigos não incardinados que podem exercer o ministério tal como o prevê o cân. 701. Todavia, por motivos teológicos, fundados na natureza do ser presbiteral, não quer que os presbíteros, que por natureza são cooperadores da ordem episcopal para o reto desenvolvimento da missão apostólica confiada por Cristo, exerçam o ministério independentemente dos Bispos aos quais foi confiada a cura pastoral de uma diocese. Por isso, o legislador veta a admissão de clérigos "acéfalos" ou "vagantes" e pró́be o exercício do ministério àquele sacerdote demitido do instituto que não encontrar um Bispo que lhe permita o exercício das ordens sob a sua jurisdição ${ }^{27}$. Como conclusão, Egaña sustenta que o religioso clérigo que não for acolhido por um período de prova e nem obteve a permissão para exercitar as ordens é um clérigo não incardinado e "acéfalo" e, portanto, está impedido de exercer o ministério. Caso seja acolhido por um período de prova ou lhe seja permitido exercer as ordens, continua sendo um clérigo não incardinado, mas não "acéfalo" ou "vagante", pois exercerá o ministério sob a jurisdição de um Bispo ${ }^{28}$. Todavia, ele não oferece uma solução para a questão do clérigo não incardinado e "acéfalo".

26 Cf. EGAÑA, Francisco Javier. Gli IVC e le SVA. Questioni canoniche: Qual è la condizione giuridica del sacerdote religioso dimesso: 1) che non viene accolto neppure in prova da un vescovo (c. 693); 2) o al quale il vescovo permette soltanto l'esercizio degli ordini sacri(can. 701)? In: Vita Consacrata 27 (1991) p. 679.

27 Ibidem. p. 680.

28 Cf. EGAÑA, Francisco Javier. Gli IVC e le SVA. Questioni canoniche: Qual è la condizione giuridica del sacerdote religioso dimesso: 1) che non viene accolto neppure in prova da un vescovo (c. 693); 2) o al quale il vescovo permette sol- 
Do quanto exposto a respeito dos problemas relativos ao tema da incardinação do religioso clérigo legitimamente demitido do instituto, convém recordar aquilo que o CIC de 1917 previa a esse respeito. Segundo o cân. $672, \S 2$ do código pio-beneditino, caso o religioso clérigo demitido do instituto não encontrasse um Bispo benévolo que o acolhesse, permitindo-lhe o exercício do ministério, a questão deveria ser submetida à Santa Sé. Tal "solução" não pode ser descartada, embora não esteja contemplada explicitamente no CIC atual. Todavia, se o religioso clérigo demitido do instituto não encontrar um Bispo benévolo que o receba, é bem provável que as razões de sua demissão tenham sido graves e, nesse caso, talvez deva refletir a respeito da possibilidade de deixar o ministério ordenado.

Por fim, tendo presente o cân. 693, o religioso clérigo recebido por um período de experiência em uma diocese, transcorrido um quinquênio, fica ipso iure incardinado na diocese, a não ser que o Bispo o tenha recusado.

\subsubsection{Não direito a ressarcimento}

O cân. 702, § 1 indica um segundo efeito importante da demissão legítima:

Qui ex instituto religioso legitime egrediantur vel ab eo legitime dimissi fuerint, nihil ab eodem repetere possunt ob quamlibet operam in eo praestitam.

A leitura do cânon se refere a efeitos que decorrem não apenas da demissão legítima, mas, também, de qualquer forma de saída legítima do instituto. Afirma-se que os que saem legitimamente de um instituto religioso nada podem dele exigir por qualquer trabalho nele prestado. Trata-se de uma norma coerente com a natureza moral e espiritual da profissão religiosa, que não tem uma índole econômica, embora tenha consequências econômicas. A vida religiosa, de fato, possui finalidades espirituais e morais, não econômicas ou de lucro, e

tanto l'esercizio degli ordini sacri(can. 701)? In: Vita Consacrata 27 (1991) p. 680. 
as relações dos membros entre si e com o instituto não são relações de trabalho subordinado ou sindicais, mas, sim, familiares. Portanto, o legislador reforça a ideia de que a atividade exercida no instituto não deve ser confundida com um contrato de trabalho e, por isso, não gera qualquer direito por força da justiça comutativa. Além disso, o cân. $668, \S 3$, estabelece que qualquer coisa que o religioso adquire por própria indústria ou em vista do instituto, adquire para o instituto. $\mathrm{O}$ que lhe advém de qualquer modo por motivo de pensão, subvenção ou seguro é adquirido pelo instituto, salvo determinação contrária do direito próprio ${ }^{29}$. Convém sublinhar que quando a pessoa faz a sua profissão religiosa, segundo as Constituições do instituto, tem consciência de tudo isso e aceita livremente tais consequências. Infelizmente, não é raro que, após deixar o instituto, seja por qual forma for, o exreligioso busque algum tipo de compensação, dirigindo-se, inclusive, ao tribunal civil, como se a sua profissão religiosa fosse uma espécie de contrato de trabalho ${ }^{30}$. Com o intuito de evitar processos civis custosos e danosos para o instituto, Jean Beyer sugere que se peça ao pro-

29 Andrés insiste na ideia de que pela via da justiça o religioso não pode exigir nada do instituto e oferece três razões para sustentar a sua posição: "1) la vida religiosa, como consagración total de la persona, fue una plena, cultual y sacrificial donación de la persona en su integridad (cf. can. 607, § 1);2) todo lo que el Religioso adquirió por el proprio trabajo o en consideración al Instituto, lo adquirió, sin excepciones, para este (can. $668, \S 3) ; 3$ ) y, quebrada la profesión, cesa automaticamente la obligación que el Instituto tenía de proporcionar a su exmiembro lo necesario para la fidelidad a una vocación abandonada (cf. can. 670)". ANDRÉS, Domingo Javier. El subsidio caritativo a los que dejan los institutos pasado, presente y futuro de la institución. In: Commentarium pro Religiosis et Missionariis 68 (1987) p. 326.

Lobina apresenta alguns princípios seguidos pela jurisprudência civil para os casos de religiosos que deixaram o instituto e entraram com ações na justiça, pleiteando algum tipo de indenização e apresenta algumas decisões dos Tribunais italianos a esse respeito. Para conhecer o conteúdo de tais decisões, ver: LOBINA, Giuseppe. L'aiuto ai religiosi che abbandonano l'istituto. In: Apollinaris 48 (1975) pp. 464-472. No Brasil, o artigo 16 do Acordo entre a República Federativa do Brasil e a Santa Sé, relativo ao estatuto jurídico da Igreja Católica no Brasil, exclui a existência de qualquer vínculo empregatício entre o religioso e o seu instituto, a não ser que fique provado o desvirtuamento da instituição eclesiástica. Cfr. Decreto Legislativo n ${ }^{\circ}$ 7107, de 11 de fevereiro de 2010, publicado no Diário Oficial Seção 1 - 12/2/2010, p. 6. 
fesso que assine uma declaração antes da profissão na qual conste que libera o instituto de eventuais exigências econômicas futuras:

... a fin d'éviter des procès civils coûteux et dommageables à l'istitut - certains ont été obligés de reprendre des religieux qui avaient abandonné l'istituti avec les responsabilités qu'ils exerçaient au moment de leur départ il sera bon de faire signer une déclaration, valable en droit civil, qui libère l'institut de ces procédures et comporte le renoncement à exiger "arriérés de salaires", subsides spéciaux, charges et fonctions occupées avant le départ. Certains instituts on pris ces mesures de prudence. Tous y sont moralement obligés, vu les conséquences que prennent les négligences, oublis et incompétences en ces matières ${ }^{31}$.

A validade desta sugestão é questionada por Lobina, pois considera que não é raro que se invoque a inconstitucionalidade de tais acordos, a violação de direitos inalienáveis, etc. Acrescenta, ainda, o quanto segue:

D'altra parte, il ricorso ad un simile espediente appare del tutto superfluo se, durante i periodi di formazione, si avrà cura di inculcare negli aspiranti alla vita religiosa il vero concetto del voto di povertà, di castità e di obbedienza e si farà capire a chiare note che l'ingresso in religione è qualcosa di ben lontano dall'adesione ad una cooperativa di produzione o ad una "impresa", il cui concetto essenziale, secondo le leggi civili, include quello del datore di lavoro e del prestatore di opera subordinato ${ }^{32}$.

31 BEYER, Jean. Le Droit de la Vie Consacrée, Paris : Editions Tardy, 1988, pp. 200-201.

32 LOBINA, Giuseppe. L'aiuto ai religiosi che abbandonano l'istituto. In: Apollinaris 48 (1975) p. 450. 
Calabrese, esclarece que o religioso demitido poderá ter direito a exigir algo do instituto não em razão do trabalho nele prestado, mas por outros motivos:

Sono fuori discussione alcuni diritti certi dei religiosi dimessi, quando esistono, per esempio il diritto a riavere la dote da parte delle religiose che escono o legittimamente o anche illegittimamente, oppure la restituzione dei beni rimasti in proprietà del religioso, ma dati ad amministrare all'istituto, oppure le pensioni a titolo personale, come le pensioni di guerra, quelle di invalidità e vecchiaia, ecc.

Non sono però motivo valido per esigere qualcosa il tempo passato dal religioso nell'istituto, l'età, la normale diminuita salute causata dagli anni, gli acciacchi dell'età, l'arricchimento dell'istituto per il lavoro del religioso, ecc. ${ }^{33}$.

O mesmo autor se pergunta se certas circunstâncias especiais não poderiam fundar o direito do religioso e a obrigação do instituto a algum tipo de ressarcimento, como, por exemplo, no caso em que o religioso tenha contraído uma doença perpétua ou debilitante devido ao trabalho que realizou em um ambiente insalubre, ou, então, no caso em que o religioso tenha sofrido algum tipo de acidente enquanto trabalhava no instituto. Segundo o autor, a práxis nesses casos nos remete ao subsídio caritativo e com isso ele não está de acordo. Para ele, em circunstâncias especiais, se está diante de um verdadeiro direito natural, superior, portanto, ao direito positivo humano ou eclesiástico, e não diante de um mero subsídio caritativo. As razões que apresenta para sustentar a sua posição são três:

$1^{\mathrm{a}}$. O CIC atual exclui apenas as reivindicações pelo trabalho prestado, mas não exclui e não contempla os casos excepcionais acima indicados que devem ser regulados por outros critérios e outras normas;

33 CALABRESE, Antonio. Istituti di Vita Consacrata e Società di Vita Apostolica, Città del Vaticano: Libreria Editrice Vaticana, 2011 (3ª ed.), p. 333. 
$2^{\mathrm{a}}$. Quando se afirma que a relação do religioso com o instituto é de família e não de trabalho subordinado, não se pode esquecer que o membro de uma família que sofre alguma desgraça no exercício de algum trabalho em prol da família tem o direito de usufruir de parte dos bens do núcleo familiar ao qual pertence;

$3^{\mathrm{a}}$. O cân. $689, \S 2$ parece reconhecer que o instituto tem o dever de manter e cuidar dos religiosos que, por causa de uma doença física ou psíquica, se tornaram inidôneos para a vida no instituto, desde que isso tenha ocorrido por negligência do instituto ou por trabalhos nele realizados. Para ele, o princípio que fundamenta esta norma poderia ser aplicado igualmente no caso de demissão, ao menos em alguma medida.

$\mathrm{O}$ autor conclui que uma vez verificadas determinadas circunstâncias especiais, como as acima indicadas, nasce o direito do religioso de pleitear algum tipo de ressarcimento e que vai além de um simples auxílio caritativo ${ }^{34}$.

\subsubsection{Dever de ajuda por parte do instituto}

Não obstante o não direito a ressarcimento por parte do demitido, há um dever que recai sobre o instituto, em conformidade com o cân. $702, \S 2$ :

Institutum tamen aequitatem et evangelicam caritatem servet erga sodalem, qui ab eo separatur.

Embora os que deixam o instituto nada possam exigir dele por qualquer trabalho nele prestado, o instituto deve observar a equidade $\mathrm{e}$

34 Cfr. CALABRESE, Antonio. Istituti di Vita Consacrata e Società di Vita Apostolica, Città del Vaticano: Libreria Editrice Vaticana, 2011 ( $3^{\mathrm{a}}$ ed.), pp. 334335. Como se verá na sequência, a questão da ajuda a ser dada àqueles que são demitidos é uma questão de equidade e de caridade e não propriamente de justiça comutativa. Os exemplos indicados por Calabrese se reportam ao tipo de trabalho realizado no instituto, em razão da profissão religiosa e da missão do instituto e, portanto, entram na solução do subsídio caritativo oferecido tendo por base a caridade e a equidade. Sendo assim, não parece muito adequado enquadrar a situação em termos de "justiça", como o fez o autor. 
a caridade evangélica para com o membro que dele se separa. Todavia, em relação ao quanto e ao como, não se pode falar nem de direitos e nem de deveres, pois não se trata de justiça comutativa, mas, sim, de equidade e caridade evangélica.

A postura a ser assumida pelo instituto conhecida por "subsídio caritativo" 35 é definida por Andrés como uma espécie de ajuda espiritual, moral, social e econômica, caso seja necessária, que o instituto deve oferecer ao religioso que dele se desliga, inspirando-se na equidade e na caridade evangélica, mas não na justiça social ou comutati$\mathrm{va}^{36}$.

A equidade é uma realidade não somente humana (natural), mas, também, canônica, dotada essa última de uma dimensão sobrenatural que "adoça" o direito, mesclando-o com a misericórdia e a caridade, corrigindo a sua inevitável abstração e unindo-o à singularidade de cada caso.

A caridade evangélica é um preceito fundamental, aglutinante de toda a vida consagrada, que se estrutura para a sua perfeição. Além de dever ser constante e sem limites, poderá, bem diferenciada da justiça, chegar muito mais longe do que ela na sua dimensão e eficácia ${ }^{37}$.

L. Ricceri destaca que o subsídio caritativo pretende ir ao encontro daqueles religiosos e religiosas que ao deixarem a vida religiosa não poderão prover à própria subsistência com os próprios bens. Os bens têm aqui um significado extensivo de qualquer meio de sustento. Em primeiro lugar, o trabalho, como fonte primária do próprio sustento, como, também, as capacidades pessoais, os títulos de estudo, as qualificações profissionais e outras circunstâncias que devem ser ava-

35 Em relação à história documental e codificada deste subsídio caritativo, do CIC de 1917 até a codificação atual, ver: ANDRÉS, Domingo Javier. El subsidio caritativo a los que dejan los institutos pasado, presente y futuro de la institucion. In: Commentarium pro Religiosis et Missionariis 68 (1986), p. 321-327. Para uma abordagem bem mais recente sobre o tema, com indicações de natureza histórica, jurisprudencial e algumas propostas práticas, Cf. CARVAJAL, Delfina Moral. Il dovere dell'istituto verso il religioso che se ne separa. Prassi e prospettive. In: Revista Española de Derecho Canónico, 76 (2019) pp. 711-737.

36 Cf. ANDRÉS, Domingo Javier. Separazione dall'Istituto. In: Dizionario Teologico della Vita Consacrata. Milano: T. Goffi e A. Palazzini, 1994, p. 1604. Ibidem. p.1604. 
liadas caso a caso. Somente quando aquele que foi demitido, não obstante a sua sincera vontade de prover o próprio sustento, encontra-se na impossibilidade de fazê-lo, é que deve intervir o instituto com a sua ação subsidiária, ajudando-o caritativamente no modo que for mais adaptado à sua situação concreta. É justamente este acordo entre o instituto e o demitido que não raramente produz uma diversa avaliação de parte a parte e dificulta o estabelecimento do quantum debeatur ex caritate $^{38}$.

O mesmo autor sustenta que não faria muito sentido um discurso unívoco nesta matéria, pois as situações dos religiosos que deixam o instituto são pessoais e diferentes, sendo impraticável se chegar a um denominador comum. Ele propõe que os religiosos que deixam o instituto sejam divididos em três categorias. Em cada uma delas o tema do subsídio caritativo se coloca de modo diverso.

Uma primeira categoria seria formada por aqueles que possuem uma situação privilegiada desde um ponto de vista econômico. Seriam aqueles que possuem um bom título de estudo, carreira, experiência, qualificação profissional e uma colocação já assegurada no mercado de trabalho. Tais pessoas, na verdade, são devedoras ao instituto por tudo o que receberam e não vice-versa, não cabendo qualquer subsídio caritativo.

Uma segunda categoria seria formada por aqueles que saem do instituto intelectual e socialmente promovidos, com uma boa formação humana e civil, dotados de saúde, de capacidade laborativa e habilidades diversas, suficientemente qualificados em alguma arte, embora, de modo mais modesto. Neste caso, para tais pessoas não será tão difícil uma inserção no mundo do trabalho e as dificuldades que enfrentarão não serão insuperáveis. Aqui, o subsídio caritativo dado pelo instituto, com compreensão e devida generosidade, seria suficiente para retomarem a própria vida.

Uma terceira categoria é a que traria maiores dificuldades. Seriam os religiosos em idade avançada, ou pessoas física ou moralmente com muitos limites e sérias dificuldades para prover a própria vida

38 Cf. RICCERI, L. Il sussidio economico da concedersi ai religiosi che lasciano il loro istituto. In: Sacra Congregatiopro Religiosis et Institutis Saecularibus (SCRIS) 1 (1975), p. 173. 
com a devida dignidade. Neste caso, exaurida a reserva do subsídio caritativo, se privados da assistência social, não estariam em condições de prover decorosamente a si mesmos ${ }^{39}$.

Das três categorias mencionadas, o subsídio caritativo representaria uma dificuldade maior para esta última, pois se limitaria a uma ajuda temporária. Ricceri sugere, então, cinco critérios para uma justa solução de eventuais problemas:

$1^{\circ}$. Uma legislação universal e detalhada sobre este tema não é possível e nem oportuna. Seria melhor estabelecer alguns princípios gerais e fornecer algumas linhas orientativas que fossem adaptadas às diversas situações;

$2^{\circ}$. A passagem do estado religioso para o secular é sempre um momento delicado e difícil: a pessoa que faz esta opção é afetada em sua totalidade e é justamente essa totalidade que precisa ser levada em conta. Por isso, o auxílio econômico, essencial e urgente, não é suficiente e, talvez, nem o mais importante. É preciso proximidade humana e caridade evangélica;

$3^{\circ}$. Por outro lado, os princípios de equidade e caridade, em base aos quais são definidos os subsídios, são igualmente válidos, tanto para quem sai quanto para aqueles que permanecem, ou seja, o instituto não pode colocar sobre os que permanecem o peso da ajuda dada àqueles que deixam o instituto;

$4^{\circ}$. Quem deixa a vida religiosa não pode exigir nada em nome da justiça comutativa. Este princípio deve sempre ser recordado e está na base de qualquer solução que se pretenda dar ao subsídio caritativo. Somente esta condição salva a natureza da vida religiosa. A profissão religiosa necessariamente porta consigo importantes consequências jurídicas, mas permanecem no âmbito sobrenatural, pois se trata de uma consagração a Deus que nada tem a ver com os contratos e as relações típicas e próprias do mundo do trabalho;

$5^{\circ}$. Os subsídios e os auxílios econômicos que serão dados aos que deixam o instituto, não tendo por base a justiça, mas, sim, a equidade e a caridade, devem ser definidos caso a caso, partindo

39 RICCERI, L. Il sussidio economico da concedersi ai religiosi che lasciano il loro istituto, SCRIS 1 (1975), pp. 174-175. 
da real situação concreta de cada um e não teria como ser diferente ${ }^{40}$.

É preciso reconhecer que certas situações merecem particular atenção, como é o caso daqueles que deixam a vida religiosa após anos de atividade no instituto e já com uma certa idade, sem ter qualquer patrimônio pessoal ou bens de família para recomeçar a própria vida. Não raramente tais religiosos, mesmo tendo algum título de estudo válido em âmbito civil, devido à idade e a tantos outros fatores, encontram-se em uma situação de marginalização e acabam por se

40 O mesmo autor, ao concluir o seu artigo a respeito do subsídio caritativo, oferece importantes sugestões para resolver o problema. Segundo ele, as possibilidades de ajuda econômica poderiam ser reduzidas a três denominadores comuns: a) medidas preventivas; b) ajuda oferecida fora das estruturas de previdência social; c) ajudas oferecidas no âmbito das estruturas de previdência social.

a) As medidas preventivas por ele indicadas seriam as seguintes: favorecer a aquisição de títulos de estudos reconhecidos civilmente; preparar para algum tipo de trabalho aqueles que por qualquer razão não possam obter títulos qualificados que, no caso de saída do instituto, possa ajudá-los a ingressar no mercado de trabalho; só aceitar na vida religiosa aqueles que forem julgados aptos a se manterem com o próprio trabalho;

b) Em relação à ajuda oferecida fora das estruturas de previdência social, Ricceri faz uma distinção entre casos ordinários e extraordinários. Nos primeiros, o instituto ofereceria o subsídio caritativo não como um presente, mas, sim, como uma substancial e realista contribuição, tendo em vista a satisfação das primeiras necessidades, enquanto a pessoa procura uma colocação no mercado de trabalho. Seria possível oferecer a quem deixa o instituto a possibilidade de concluir os seus estudos ou realizar algum curso profissionalizante, como, também, valer-se da influência para ajudar a pessoa a arranjar um emprego, a partir das qualidades e habilidades pessoais que tem. Nos segundos, a caridade e a equidade exigem que sejam dados à pessoa em graves dificuldades, ou até mesmo doente ou impotente, uma ajuda proporcionada e por todo o tempo necessário; no caso de incapacidade para prover a si mesma a ajuda material e moral deverá ser contínua;

c) Por fim, no caso de ajuda prestada através de estruturas assistenciais especiais, as propostas são as seguintes: criação de organismos de seguridade social que deem suporte para a situação de doença, invalidez e idade avançada, seja no âmbito do instituto, seja no âmbito de assistência do próprio Estado; inscrição obrigatória de todos os membros dos institutos religiosos nos institutos de previdência do Estado; criação de um fundo do próprio instituto ou, então, reunindo diversos institutos, para ajudar aos que deixam a vida religiosa. Cfr. RICCERI, L. Il sussidio economico da concedersi ai religiosi che lasciano il loro istituto. In: SCRIS 1 (1975), pp. 177-181. 
tornar um "peso social" que recai sobre outros (no caso, a própria família). Quando o religioso é um sacerdote que não foi acolhido ou incardinado em uma diocese, caso se encontre privado de meios para o próprio sustento, é necessário ajudá-lo. Jean Beyer observa que no caso de negligência ou de má vontade do instituto em relação ao religioso que necessita de ajuda é possível recorrer a autoridade competente, diocesana ou romana ${ }^{41}$.

Por fim, em relação às perspectivas futuras deste subsídio caritativo, Andrés prevê uma evolução que, segundo ele, poderá percorrer os seguintes passos:

1) instaurazione o consolidamento di possibili o già reali sistemi preventivi di assicurazione sociale delle persone, sia interni che esterni; 2) creazione o aumento di uffici e segretariati che razionalizzino, sistemino e programmino il reinserimento umano, sociale e lavorativo di quanti si secolarizzano; 3) incremento dell'associazionismo degli stessi secolarizzati, fra di loro e con gli istituti, allo scopo di migliorare l'entità, la qualità e l'esistenza continuata non solo né tanto del sussidio caritativo, quanto soprattutto della globalità dei vincoli che unirono e li continueranno a unire alla famiglia religiosa, alla quale canonicamente appartennero $^{42}$.

\subsubsection{Relatório a ser enviado à Sé Apostólica}

O último efeito da demissão aparece indicado pelo can. 704:

De sodalibus, qui ab instituto sunt quoquo modo separati, fiat mentio in relatione Sedi Apostolicae mittenda, de qua in can. 592, $\$ 1$.

41 Cf. BEYER, Jean. Le Droit de la Vie Consacrée. Paris: Editions Tardy, 1988, p. 200.

42 ANDRÉS, Domingo Javier. Separazione dall'Istituto. In: Dizionario Teologico della Vita Consacrata. Milano: T. Goffi e A. Palazzini, 1994, p.1604. 
O cân. 592 estabelece que para melhor alimentar a comunhão dos institutos com a Sé Apostólica, no modo e no tempo por ela determinados, cada Moderador supremo deve transmitir à Santa Sé, um breve relatório do estado e da vida do instituto. Nesse relatório devese fazer menção dos membros que, de algum modo, se separaram do instituto, conforme estabelece o cân. 704. O relatório solicitado, não é um dado meramente burocrático, pelo contrário, pois tem por finalidade reforçar a comunhão com a Sé Apostólica, apresentando a ela as informações necessárias a fim de que possa ter elementos suficientes sobre a realidade de cada instituto e, assim, poder se fazer próxima e exercitar convenientemente a sua responsabilidade pastoral, inclusive com algum tipo de ajuda. Além disso, a separação de um membro de um instituto, como também a profissão religiosa no instituto, não é um fato privado que diz respeito apenas ao indivíduo e ao instituto, mas, sim, é um fato público, que interessa a toda a Igreja e, por conseguinte, é normal que tal situação seja conhecida pela Santa Sé ${ }^{43}$.

\section{Conclusão}

O Papa Francisco, com o motu proprio $C V$, deu uma solução para um problema específico. É preciso considerar que a ausência ilegítima da casa religiosa, como, também, as demais causas de demissão, são sempre uma oportunidade para que o instituto reveja os critérios de admissão, a seriedade de sua formação, o empenho dos seus superiores, a vida espiritual dos seus membros e a fidelidade ao carisma. Tais condutas "irregulares", quando repetidas, podem ser um sinal de que, talvez, alguma coisa não esteja funcionando como deveria. Caberia, então, aos membros de cada instituto um esforço conjunto e empenho redobrado para recuperar os "irregulares", quando possível, e evitar que tais situações voltem a se repetir, afetando, assim, a credibilidade do testemunho a ser dado. Ao mesmo tempo, é preciso admitir

43 Para um amplo estudo a respeito deste relatório, ver: REYNOSO, R. A. Anotaciones a: CIVCSVA: Epistulae, Criteria de notitiis ad statum et vitam institutorum religiosorum et societatum vitae apostolicae spectantibus, quae cum Sede Apostolica, quibusdam temporis intervallis, communicanda sunt. In: Commentarium pro Religiosis et Missionariis 69 (1988) pp. 413-421. 
que o instituto jurídico da demissão dos religiosos é uma espécie de "remédio amargo" previsto pela Igreja em favor dos institutos quando se depara com membros que, com uma conduta evidentemente contrária aos valores da própria consagração, afetam a vitalidade do instituto de pertença, da vida religiosa e, portanto, da própria Igreja. Ao se optar por tal "remédio", deve-se observar a lei.

\section{Bibliografia}

Fontes e documentos

FRANCISCO. Carta apostólica sob forma de motu proprio Vos Estis Lux Mundi. (on -line) <http://www.vatican.va/content/francesco/pt/motu _proprio/documents/papa-francesco-motu-proprio-20190507_vos-estislux-mundi.html>.

SACRA CONGREGATIO RELIGIOSORUM. Decr. Quum singulae, 16 mai. 1911. In: AAS 3 (1911) n. 18, 237.

\section{Estudos}

ANDRÉS, Domingo Javier. El subsidio caritativo a los que dejan los institutos pasado, presente y futuro de la institución. In: Commentarium pro Religiosis et Missionariis 68 (1987) p. 326.

ANDRÉS, Domingo Javier. Separazione dall'Istituto. In: Dizionario Teologico della Vita Consacrata. Milano: T. Goffi e A. Palazzini, 1994, p. 1604.

ANDRÉS, Domingo Javier. Le forme di vita consacrata. Commentario teologico - giuridico al Codice di Diritto Canonico. Roma: Ediurcla, 2015 ( $7^{\mathrm{a}} \mathrm{Ed}$.).

BEYER, Jean. Le Droit de la Vie Consacrée. Paris: Editions Tardy, 1988.

CALABRESE, Antonio. Istituti di Vita Consacrata e Società di Vita Apostolica. Città del Vaticano: Libreria Editrice Vaticana, 2011 ( $3^{\mathrm{a}} \mathrm{Ed}$.). 
CARVAJAL, Delfina Moral. Il dovere dell'istituto verso il religioso che se ne separa. Prassi e prospettive. In: Revista Española de Derecho Canónico, 76 (2019) pp. 711-737.

CHIAPPETTA, Luigi. Il Codice di Diritto Canonico. Commento giuridico-pastoral. Vol. 1, Roma: Edizione Dehoniane, 1996.

DE PAOLIS, Velasio. La vita consacrata nella Chiesa.Venezia: Marcianum Press, 2015.

EGAÑA, Francisco Javier. Gli IVC e le SVA. Questioni canoniche: Qual è la condizione giuridica del sacerdote religioso dimesso: 1) che non viene accolto neppure in prova da un vescovo (c. 693); 2) o al quale il vescovo permette soltanto l'esercizio degli ordini sacri(can. 701)? In: Vita Consacrata 27 (1991) p. 679.

JAEGER, David-Maria A. Alcuni appunti sui religiosi nel Codex Canonum Ecclesiarum Orientalium. In: AA.VV. Il Diritto Canonico Orientale nell'ordinamento ecclesiale. Città del Vaticano: Libreria Editrice Vaticana, 1995, p. 188.

LOBINA, Giuseppe. L'aiuto ai religiosi che abbandonano l'istituto. In: Apollinaris 48 (1975) pp. 464-472.

REYNOSO, R. A. Anotaciones a: CIVCSVA: Epistulae, Criteria de notitiis ad statum et vitam institutorum religiosorum et societatum vitae apostolicae spectantibus, quae cum Sede Apostolica, quibusdam temporis intervallis, communicanda sunt. In: Commentarium pro Religiosis et Missionariis 69 (1988) pp. 413-421.

RIBEIRO, Valdinei de Jesus. A demissão dos religiosos por ausência ilegítima da casa religiosa após o motu proprio Communis Vita (Parte I). In: Scientia Canonica. Vol. 2, no 3 (2019) pp. 55-82.

RIBEIRO, Valdinei de Jesus. La dimissione dei religiosi nella legislazione della Chiesa Latina dal Codice del 1917 al Codice del 1983 con speciale riferimento alle legislazioni particolari. Roma: Pontifícia Universidade Lateranense, 2000. 
RICCERI, L. Il sussidio economico da concedersi ai religiosi che lasciano il loro istituto. In: Sacra Congregatiopro Religiosis et Institutis Saecularibus (SCRIS) 1 (1975) p. 173-181. 